\title{
3
}

\section{Modeling Urban Hydrological Processes and Management Scenarios at Different Temporal and Spatial Scales}

\author{
Manfred W. Ostrowski
}

The impact of urbanisation on the hydrological cycle has been discussed for several decades. Urbanisation is frequently said to cause increasing flood peaks and volumes. While this statement is certainly true for volumes, it has not been generally proven concerning flood peaks. Unfortunately, the literature is dominated by subjective opinions rather than by scientifically-based, objective evidence.

To cope with increasing floods, politicians, the public and scientists argue that local end-of-pipe storm water management practices, rather than source control measures, can largely contribute to the reduction of flood peaks.

However, agreement has been reached on the effect of urbanisation, depending on the size of the river basin and related characteristics such as location of urbanisation, duration and intensity of precipitation and so forth. The following numbers are based on German land use statistics. Small basins up to $10 \mathrm{~km}^{2}$ in area if developed completely have a degree of imperviousness that might reach $50 \%$. The effective impervious area of large basins, such as the River Rhine or River Elbe, is comparatively small, reaching 2 to $3 \%$. In large river basins about $12 \%$ of the land surface is typically developed, with a maximum of $50 \%$ being impervious. However, only $50 \%$ are directly connected to urban drainage systems. In the opinion of the author, it is most important to

Ostrowski, M. 2002. "Modeling Urban Hydrological Processes and Management Scenarios at Different Temporal and Spatial Scales." Journal of Water Management Modeling R208-03. doi: 10.14796/JWMM.R208-03.

(C) CHI 2002 www.chijournal.org ISSN: 2292-6062 (Formerly in Best modeling practices for Urban Water Systems. ISBN: 0-9683681-6-6) 
consider the size of a basin when assessing (i) the effect of urbanisation, or (ii) measures to compensate resulting negative effects e.g. measures to control the sources of storm water. It is well known that spatial scales such as basin size and temporal scales such as time steps are important issues in modeling environmental processes.

Although the scale problem in urban drainage is not new, traditional urban drainage technology did not consider it - it has mostly been considered separately from basin-wide hydrologic processes. Fast and effective drainage has been the major objective until recently. Today, integrated concepts of storm water management and treatment are slowly but surely replacing these old concepts. These integrated concepts may be described as "centralized", "semicentralized" and "de-centralized". Processes at these different scales occur in an integrated river basin, and are sensitive to different intensities. For this and several other reasons, such as accuracy and computational efficiency, the river basin and its related hydrological and hydraulic processes must be decomposed carefully.

This chapter introduces the problem of spatial and temporal scales in urban drainage modeling, and recommends how suitable scales may be chosen. Of major importance in this discussion is the effect of urbanisation on floods, in particular the effect of source control measures on floods, and their modeling and integration in large river basin models at the meso scale. Only distributed, conceptual approaches with adequate physical background are considered.

\subsection{Scale Issues in Hydrological Modeling}

Over the last decade, the question of scale in modeling hydrological and hydraulic processes in space and time has been of wide interest. However, most hydrologic research activities in this field have been directed towards natural processes rather than urban hydrology. Perhaps in Germany, and to some extent in Europe, this can be explained by the fact that research on natural hydrological processes has more and more become the domain of natural sciences such as physics and physical geography, while urban hydrology is still mainly based in Civil Engineering. Traditionally, knowledge transfer between the natural sciences and engineering subjects, such as urban drainage technology and engineering hydrology, has been slow.

Still, basic expressions and definitions are transferable. An important contribution was given by Bloeschl (1996). His work can be considered to be fundamental. He firstasks the question: how can point information (measurement or computational result) be regionalised, i.e. transferred to the surrounding 
area? This question is difficult to answer for different reasons. Point measurements of extreme precipitation events resulting from convective storms as well as flood hydrographs derived from rainfall via models should not be simply integrated through superposition using linear approaches. When changing scales from a highly distributed and possibly physically-based model to a coarser model, validity limits of differential equations are normally violated. Change of complexity is associated with non-linearity.

For reliable assessment of applications of source control measures and their impact on flood magnitudes, this question is of dominant importance. Many source control measures such as infiltration do not reduce flow volumes and thus can contribute to floods in positive and negative ways according to pathways between sub surface flow and river flow. Similar questions, but even in more complex form have to be asked in the context of integrated river basin management, a topic being intensively discussed in Europe as well as North America.

According to Bloeschl (1996), increasing computer power now allows modelers to change from low to higher spatial and temporal resolution.

Transferring and integrating point measurements and other information to a region is called "upscaling", while the reverse is called "downscaling". In this context upscaling means to integrate measurements, data, parameters and results used in highly distributed urban drainage models, including source control measures on the micro scale, into less distributed hydrologic river basin models at the meso scale.

It is quite remarkable that urbanisation is hardly mentioned in recent research projects on hydrological scaling, although its influence on regional floods is intensively and frequently discussed.

In the framework of deterministic models, process scales to be considered are characteristic length and time scales. The spatial scale covers the area of the river basin, the temporal scale includes the choice of the simulation period and the computational time step used.

\subsubsection{Choice of Spatial and Temporal Scales}

Definitions here have been taken from meteorology, despite the obvious differences between the disciplines. Applied distributed hydrologic modeling usually deals with spatial scales in the range of a few hectares to several square kilometres. Temporal scales related to these spatial scales cover a range of time steps between few minutes on one hand to one day on the other.

Figure 3.1 gives an overview of spatial and temporal scales used in hydrology. 


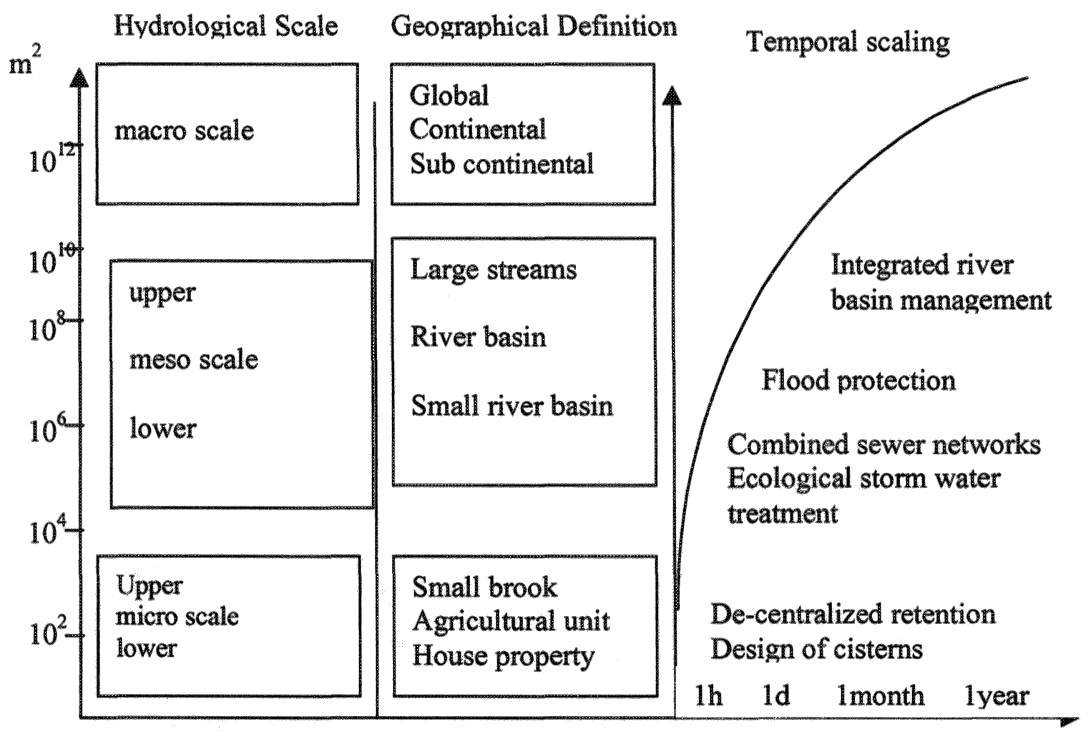

Figure 3.1 Spatial and temporal scales.

The optimum choice of scale depends mainly on the following six factors:

- type of investigation,

- homogeneity,

- process intensities,

- data availability,

- computational stability, and

- computational efficiency.

\subsubsection{Scope of Investigation}

Temporal and spatial scales can vary considerably, depending on the scope of the investigation. Foe example, in integrated flood hydrology, regional questions have to be answered, leading to basin-wide considerations. These studies are normally performed at the meso scale.

Models used for this purpose have been deterministic, conceptual models. However, due to improved data availability and its convenient storage in geographical and time series information systems, the spatial and temporal resolution has become increasingly more detailed. Digital elevation data with 25 $\mathrm{m}$ grid length and digital time series in 5-minute time steps can be expected to become standard in the next decade. 
In urban hydrology, local and micro scale problems have to be analysed and solved. Modeling scales applied in this field still differ according to the scope of the study. Often, the design of sewers is still based on the rational method, while improvement of existing systems is based more and more on hydrodynamic models.

Recently, innovative, integrated concepts for storm water management in the sense of best management practices (BMPs) have been developed. These concepts, as well as that of extreme floods, require the combined simulation of rural and urban areas at an adequate level of sophistication and suitable time and space scales. It can be expected that this combined modeling will become increasingly common in practical design. At the moment, however, it is still a field of interest in applied research.

\subsubsection{Homogeneity}

The term homogeneity is used to describe the variability of spatial characteristics of the system being investigated. Each river basin is an individual combination of several hydrologic and hydraulic elements. The algorithms applied for the simulation of hydrologic and hydraulic processes contain parameters which have more or less physical significance, e.g. saturated and unsaturated hydraulic conductivity. When elements are initially defined, it is necessary to assess the homogeneity of parameters within the element. Often so called elementary units are used in the context of spatial resolution. These are sub areas which show little variability of important characteristics. In the best case they combine homogeneous land use, homogeneous soil characteristics and constant slope conditions. In this respect homogeneity of basin characteristics defines the spatial scale required. Neglecting this issue by inadequate averaging will probably lead to the loss of hydrologic extremes in long-term distributed simulation. The same applies to hydraulic system characteristics. If hydraulic characteristics such as slopes, cross sections, and roughness change within one element, that element has to be further segmented into more homogeneous sub-elements. Again, averaging can lead to missing important changes from one process to the next, e.g. from free surface flow to pressure flow. This requires that singular hydraulic structures of importance, e.g. in the case of reservoir modeling, have to be considered separately.

\subsubsection{Process Intensities}

Spatial and temporal scales must be chosen to adequately account for the intensities of the processes modeled. When determining flood hydrographs and peaks it has to be taken into account how temporal averaging will influence the target values such as volumes and peaks. If modules for the future scenario are 
combined to model complex basin systems, it must be seen that sub systems such as the sewer system, and natural basin and groundwater systems, are determined by different process dynamics. Reaction times to rainfall or time of concentration in sewer systems are a few minutes, in natural hydrologic surface and near surface flow it might be a few hours, while for groundwater it might be several days to weeks. For source control measures, the situation is even worse, as BMPs are usually unevenly distributed in a catchment, they have reaction times of one to two minutes and they link high intensities of rainfall and runoff with much slower groundwater reactions.

Also, besides retention processes at different spatial scales, rainfall intensity as input to the system is a critical issue with respect to scale.

One further aspect needs special consideration, viz. the dependence on spatial and temporal scales of model parameters representing rates and velocities such as saturated hydraulic conductivity. As rates $(\mathrm{L} / \mathrm{T})$ include both the length and the time scale, this appears quite logical. This means that e.g. hydraulic conductivity has quite different physical significance and absolute values when used for (a) source control measures (infiltration ditches), for (b) infiltration modeling in rainfall runoff catchment models, or for (c) groundwater modeling.

\subsubsection{Data Availability}

The importance of data of the respective hydrologic system and its availability vary widely between rural and urban areas. In rural areas, topography, soil characteristics, vegetation type and river geometry are important. In urban areas emphasis is put on the technical description of developed areas and drainage systems. Quasi-natural parts of urban areas and their characteristics are neglected in most maps and urban models. In other cases they have been completely changed by human activities and their hydrological behaviour is more or less unknown.

\subsubsection{Computational Stability}

Some of the mathematical solutions of the differential equations require numerical methods, e.g. when solving the St. Venant equations for simulating shallow water waves in pipes and rivers or the Darcy Richard's equations to simulate water movement and storage in unsaturated porous material. These numerical methods can become unstable, if spatial scales $\Delta \mathrm{x}$ and temporal scale $\Delta t$ are not adequately chosen. For example, in hydrodynamic sewer models with explicit solution schemes, the Courant Criterion defines limits for the choice of scales. For several reasons the related space data and time series must 
be available at the same scale, e.g. for boundary conditions, which often have to be estimated.

\subsubsection{Computational Efficiency}

Although computational power and storage capacities are constantly increasing, computational efficiency still remains a bottleneck. For practical applications using potentially available data and improved non-linearnumerical models, the necessary computer power will not be available in the near future. Because it is desirable to use best available data and models with the limited computational power currently available, it is necessary to run coupled sub models at different scales. Suitable interfaces for the coupling process are required. Alternatively data and parameters on a micro scale can be aggregated to use the coarser information directly. This data aggregation can be as simple as arithmetic or geometric averaging, but can also be a non-linear procedure. In any case, it has to be proved scientifically that these procedures lead to appropriate representation of a sub system on a larger scale. This has been done when highly resolved information on sewer networks used for hydrodynamic simulation is aggregated to be used in storm water management models. However, in the context of source control, aggregation procedures are still to be developed e.g. to represent multiple infiltration facilities in one space element, or to model the behaviour of many storm water cisterns that are constructed on a single property. Figure 3.2 depicts spatial and temporal scales that are frequently used in hydrological modeling for different purposes. Evidently aggregation of urban catchment characteristics and drainage systems becomes compulsory when changing model scales. Obviously, there are several steps to be overcome between detailed micro scale modeling of de-centralized (source control) measures, and the integration of this inhomogeneous mixture in meso-scale models.

\subsection{Structure and Scales of Existing Models}

Further model development is often achieved by modification and improvement of existing models. Some practically applied models used by the author for teaching and research purposes are listed in Table 3.1 with respect to structure and spatial scaling. For characterisation of models and scales, four types of elements are used:

Collecting areas

Transport elements

Distribution elements

Reservoirs
Dimension $\mathrm{L}^{2}$

Dimension L

none

Dimension $\mathrm{L}^{3}$ 


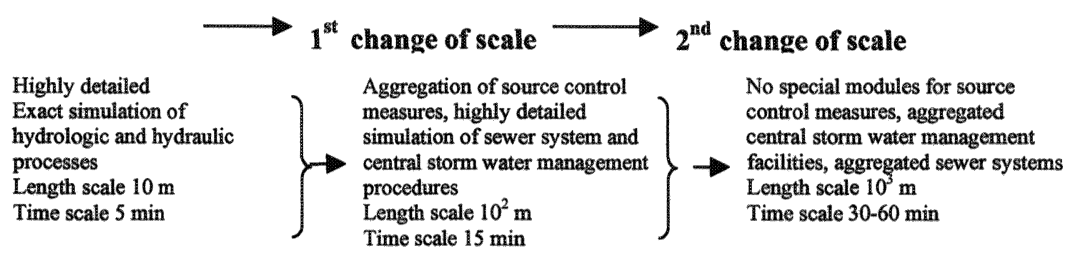

De-central storm water Management Planning

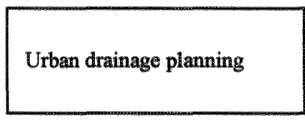

Water pollution control and flood protection planning

- Rain barrels

- Cisterns

- Infiltration trench

- Green roofs

- Aggregated de-central measures

- Sewer systems

- Additional and alternative storm water treatment
- Aggregated and simplified drainage systems including major overflows and treatment plants
- Simplest consideration of impervous urbanised areas

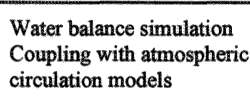

Water balance simulation Coupling with atmospheric circulation models

\section{4 - Aggregation of} developed area

Integrated river basin management

Regional flood protection planning

Use of simple coefficients such as percentage of impervious urban areas combined with other impervious areas Length scale $10^{5} \mathrm{~m}$

Time scale 3- 24 h

Further averaging of information using coefficients, times of concentration and flow Length scale $10^{4} \mathrm{~m}$ Time scale $1-3 \mathrm{~h}$

\section{$\leftarrow \quad 4^{\text {th }}$ change of scale $\leftarrow \quad 3^{\text {rd }}$ change of scale}

Figure 3.2 Different scales for modeling urban impacts as part of integrated catchment modeling.

The spatial scale starts from a few hundred square metres when modeling houses and properties in planning single structures and ends at several ten thousand square kilometres when simulating floods in large basins.

The temporal scale starts with a few seconds for multi dimensional hydrodynamic models and ends with several hours up to one day for the time step used. Table 3.1 shows some examples of existing models including elements and scales assigned.

RENSIM simulates storm water usage tanks on the basis of single houses or properties for a given climatic location and a special user community such as household, school etc (Bettmann, 1998). Assuming market prices and interest rates the optimum size of cisterns is determined by long term simulation.

SWIFT serves for planning de-centralized and semi-centralized measures for ecological storm water management. Included are measures for avoiding 
Table 3.1 Coupling of differently scaled models including urbanisation effects.

\begin{tabular}{|c|c|c|c|c|c|c|}
\hline Model & $\begin{array}{l}\text { Time } \\
\text { scale } \\
\text { min }\end{array}$ & $\begin{array}{l}\text { Space } \\
\text { scale } \\
\mathrm{m}^{2}\end{array}$ & $\begin{array}{l}\text { Collector } \\
\text { elements }\end{array}$ & $\begin{array}{l}\text { Transport- } \\
\text { element }\end{array}$ & $\begin{array}{l}\text { Distribution } \\
\text { element }\end{array}$ & Reservoir \\
\hline RENSIM & 5 & $10^{2}$ & Roof, yard & $\begin{array}{l}\text { Flumes and } \\
\text { pipes }\end{array}$ & $\begin{array}{l}\text { Overflow, } \\
\text { withdrawal, } \\
\text { supplementar } \\
\text { y supply }\end{array}$ & $\begin{array}{l}\text { Cistern } \\
\left(10^{0} \mathrm{~m}^{3}\right)\end{array}$ \\
\hline SWIFT & 5 & $10^{2}$ & $\begin{array}{l}\text { Roof, yard, } \\
\text { pervious } \\
\text { areas }\end{array}$ & $\begin{array}{l}\text { Flumes, } \\
\text { pipes, } \\
\text { sewers, } \\
\text { ditches }\end{array}$ & $\begin{array}{l}\text { Overflows, } \\
\text { withdrawals, } \\
\text { supplementar } \\
\text { y supply }\end{array}$ & $\begin{array}{l}\text { Cistern, ditch, } \\
\text { gravel trench } \\
10^{1} \mathrm{~m}^{3}\end{array}$ \\
\hline SMUSI & 5 & $10^{4}$ & $\begin{array}{l}\text { Impervious } \\
\text { areas } \\
\text { Pervious } \\
\text { areas }\end{array}$ & Sewers & $\begin{array}{l}\text { Storm water } \\
\text { overflows, } \\
\text { Basin } \\
\text { overflows }\end{array}$ & $\begin{array}{l}\text { Storm water } \\
\text { overflow and } \\
\text { retention basins, } \\
10^{2} \mathrm{~m}^{3}\end{array}$ \\
\hline MOUSE & $5 \mathrm{sec}$ & $10^{4}$ & $\begin{array}{l}\text { Impervious } \\
\text { areas }\end{array}$ & Sewers & $\begin{array}{l}\text { Storm water } \\
\text { overflows, } \\
\text { Basin } \\
\text { overflows, } \\
\text { looped } \\
\text { networks, } \\
\text { pumps }\end{array}$ & $\begin{array}{l}\text { Storm water } \\
\text { overflow and flood } \\
\text { retention basins } \\
10^{3} \mathrm{~m}^{3}\end{array}$ \\
\hline WBrM & 15 & $10^{7}$ & $\begin{array}{l}\text { Pervious, } \\
\text { impervious } \\
\text { areas }\end{array}$ & Rivers & - & - \\
\hline TALSIM & 30 & $10^{8}$ & $\begin{array}{l}\text { Pervious, } \\
\text { impervious } \\
\text { areas }\end{array}$ & $\begin{array}{l}\text { Rivers, } \\
\text { pipes, } \\
\text { canals }\end{array}$ & $\begin{array}{l}\text { Overflows, } \\
\text { distribution } \\
\text { structures }\end{array}$ & $\begin{array}{l}\text { Reservoirs and } \\
\text { flood control basins } \\
10^{6} \mathrm{~m}^{3}\end{array}$ \\
\hline
\end{tabular}

storm water such as disconnection, several infiltration techniques as well as storm water usage and de-centralized storage and retarded discharge. (Bente, 2000).

SMUSI was developed for planning combined sewer systems, including pollutant loads. Based on the German engineering code A 128 it was initially made for the assessment of storm water overflow basins. During the last five years additional alternative and extended measures have been included in the model. Now the model can also be used to plan modified combined systems. (Mehler, 2000).

MOUSE is a hydrodynamic simulation model to analyse extreme flow situations in sewer systems. It is based on the numerical solution of the combined energy and mass balance equations (St. Venant).

WBrM is a hydrological model for small river basins based on raster elements. It is strongly linked to geographical information systems. The model fills the gap between physically based models like SHE and linear conceptual models. The model itself is scale flexible according to Figure 3.3. 


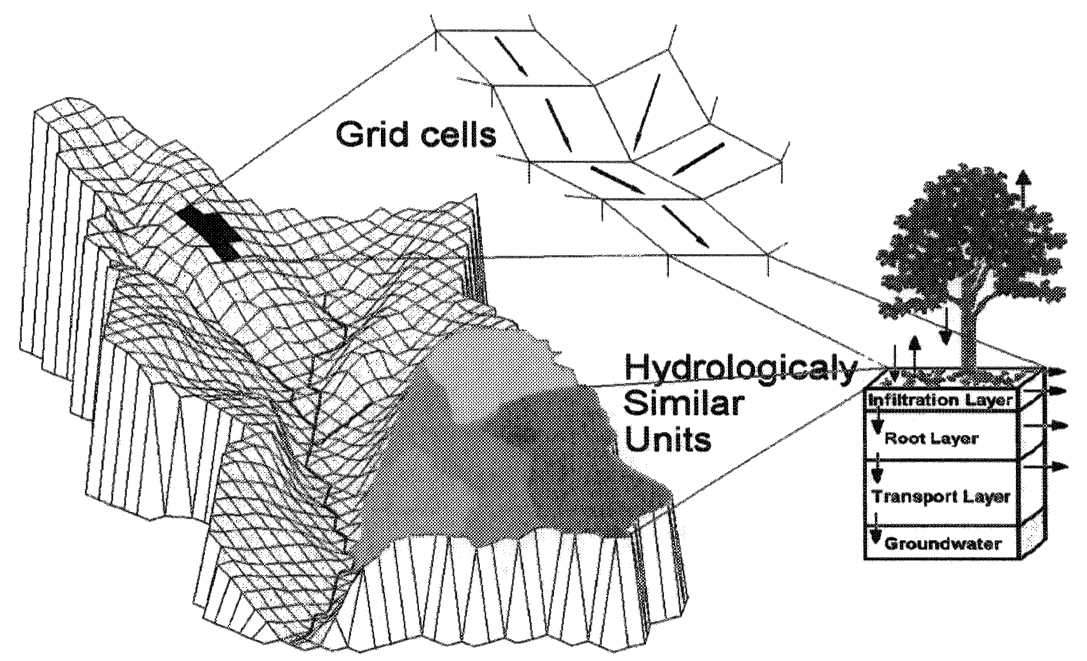

Figure 3.3 Structure of model WBrM with variable spatial scaling.

TALSIM is a modeling system for simulating complex water resources systems with an emphasis on reservoir operation. Rainfall-runoff and transport modules have been incorporated.

Suitable groundwater models might be MODFLOW of the US Geological Service or FEFLOW (Fa. WASY).

Sub models at different scales can be coupled with different methods. The most elegant and difficult way is the direct integration of models with high resolution and small scales into coarser models.

For example, it is possible to integrate or combine hydrodynamic and hydrologic sewer models to simulate surcharged parts and parts with free surface flow adequately at high speed. This approach is adequate when the processes in different separable spatial parts or elements are basically different.

More common, however, is the approach to replace a detailed system on the micro scale by a simplified aggregated system to become part of a less detailed system on the larger scale making sure that the major characteristics and basic requirements such as conservation of mass are well represented by the simplified model. In principle, the detailed principle of conservation of energy is considered less or not at all on a larger scale with respect to urban storm water management. It is common practice, e.g. for pollutant load modeling to aggregate the detailed information stored in sewer bank management systems into a system of main sewer trunks. This procedure leads to acceptable results, as the hydraulic and hydrologic behaviour of the detailed and aggregated system is similar due to homogeneity throughout the system. By 
diversification of storm water treatment technologies, adding de-centralized and source control measures, this procedure seems questionable (Sieker, 2000 and Bente, 2000). Combined with additional planning objectives such as ecology, the complexity of models increases (Mehler, 2000). Still, aggregation of spatial information seems to be the solution to maintain computational efficiency necessary for practical planning.

\subsection{Future Modeling Concepts}

Future modeling concepts must aim at requirements and boundary conditions expected in the future. Changes can be expected for the planning scope, data availability and in computer power. In addition scientific research will lead to better physically-based mathematical representations of drainage systems.

\subsubsection{New Planning Tasks and Scopes}

New fields of activity can be expected on different scales as well as for integrated approaches.

Lower micro scale:

Optimisation of source control technology on a property scale Optimisation of de-centralized and semi-centralized plants for ecologically-oriented storm water treatment

Improvement of micro-climate and aesthetic living conditions in the urban environment

Upper micro scale:

Optimisation of centralized plants for ecological storm water treatment

Implementation of storm water management plans in the early stage of regional and development planning

Development of local water concepts in the framework of the local Agenda 21 (a European standard)

Lower meso scale:

Improved water and pollutant management in small river basins

Development of sustainable regional water concepts in the framework of the regional Agenda 21.

Upper meso scale:

Integrated river basin management, e.g. according to the new European water guidelines and other recommendations of other international bodies. In this context it has to be stressed that 
developing countries will soon depend on effective BMPs including source control to improve their living conditions.

\subsubsection{Data Availability}

The collection of remote-sensed multi-temporal geographic data and their storage together with other less dynamic information in geographic information systems is in progress and has reached a remarkable standard. Aerial photographs are of high quality and together with ground data can be used to apply locally optimum BMPs. It can be expected that in the near future all geographic data for complex hydrologic modeling will be available or easy to collect in rural as well as urban areas at high resolution. Furthermore the combination of geographic 2D data and infrastructure 3D data has started and is making good progress. The most recent version 6.0 of the EPA model WASP (EPA 2001) offers promising facilities for this purpose. However, with respect to source control measures such as local infiltration, an information deficit exists concerning modeling lateral unsaturated and saturated underground flow, as no measured data is available yet.

Deficits also exist concerning hydro-meteorological information. Basically, the information density for the spatial distribution of rainfall must be considered unsatisfactory. Obviously the availability of continuous rainfall and potential evaporation data is still very limited. Assessment of micro-climatic effects or changes due to change of storm water treatment technologies from centralized to de-centralized and source control based on present monitoring networks is hardly possible.

\subsubsection{Computer Power and Efficiency}

Concerning the availability of larger computer power and innovations in information technology, the ongoing progress will continue. Parallel computing will help to make it even more efficient. It can be expected that improved computer technology will be absorbed by simulation models at lower scales, both in time and space.

A breakthrough can be expected when process models at different scales are coupled and simultaneously run on parallel computer systems. In the longer run it seems possible that neighbourhoods can also be modeled at very high resolution with all infrastructure involved, single source control measures included.

It seems to be very timely to investigate the influence of single and aggregated source control measures at all scales. To assess the necessary degree of spatial or temporal resolution, sensitivity analysis should be carried out. 


\subsection{Summary}

The impacts of urbanisation on the hydrological cycle, extreme floods included, are scale dependent. The effect on the micro scale is large at the meso scale the effect is rather limited. Storm water source control measures have proved that they can contribute to reduced local negative effects.

It is believed that these measures can also contribute effectively to regional floods in meso scale river basins. Without solid knowledge about the integrated effect of such measures the statement remains a hypothesis. Therefore, it seems timely to analyse the accumulated effects by coupling micro and meso scale hydrologic models with source control activities included. Knowledge of upscaling of urbanisation effects is very limited with respect to sub surface flows. However, it seems likely that these measures such as urbanisation itself do not have much influence on floods in large catchments. Still, basin areas between 50 and $500 \mathrm{~km}^{2}$ might be affected positively or negatively. The effect of source control measures which do not reduce flow volumes due to increased evapotranspiration (such as green roofs) is very difficult to predict.

It must be stressed that a variety of suitable sub models are available, their integration into integrated or coupled complex models is an urgent problem which should be tackled soon.

\section{Acknowledgment}

This work has partly been funded by the European Commission under project FRAMEWORK, EC contract ENV4-CT97-0529.

\section{References}

Bente, S., 2000: Ein Software-Werkzeug zur Voreinschätzung der wasserwirtschaftlichen Auswirkungen von Massnahmen der naturnahen Regenwasserbewirtschaftung, Dissertation am Institut für Wasserbau und Wasserwirtschaft, Fachbereich Bauingenieurwesen der TU Darmstadt, eingereicht

Bettmann, Th., 1998: Dezentrale Regenwasserbewirtschaftung un deren Auswirkunen auf die Regenwasserbehandlung in urbanen Gewässereinzugsgebieten, Mitteilungen des Instituts für Wasserbau und Wasserwirtschaft der TU Darmstadt, Heft 104

Blöschl. G., 1996: Scale and Scaling in Hydrology, Wiener Mitteilungen, Wasser Abwasser - Gewässer, Band 132 
Deutsche Forschungsgemeinschaft, 1992: Regionalisierung in der Hydrologie, Berichtsband zum gleichnamigen Schwerpunktprogramm

EPA(2001): Water Quality Analysis Simulation Program (WASP), Version 6.0, Draft User's Manual, Downloaded from www.epa.gov/region4/water/tmdl/tools/ wasp.htm, Chapter 4.3 Spatial Graphical Analysis

Mehler, R., 2000: Mischwasserbehandlung - Verfahren und Modelierung, Dissertation am Institut für Wasserbau und Wasserwirtschaft der TU Darmstadt, Heft 113

Sieker, H. , 2000: Generelle Planung der Regenwasserbewirtschaftung in Siedlungsgebieten, Mitteilungen des Instituts für Wasserbau und Wasserwirtschaft, in press 